\title{
A BRIEF REVIEW ON NDT\&E METHODS FOR STRUCTURAL AIRCRAFT COMPONENTS
}

\author{
Angelika Wronkowicz-Katunin \\ Silesian University of Technology, \\ Institute of Fundamentals of Machinery Design, Gliwice, Poland \\ angelika.wronkowicz-katunin@polsl.pl
}

\begin{abstract}
The paper presents a summary of non-destructive testing and evaluation (NDT\&E) methods applied in inspections of structural aircraft components. This brief review covers the most commonly applied methods such as visual and penetrant inspections, tap-testing, eddy current inspections, shearography, thermography, acoustic emission testing, radiographic and tomographic inspections, and ultrasonic inspections. The general operating principles of these methods as well as their main advantages, limitations and application areas are described below.
\end{abstract}

Keywords: NDT\&E methods, non-destructive testing, non-destructive evaluation, aircraft structures, composite structures

\section{INTRODUCTION}

An aircraft inspection can range from a preflight or postflight inspection which is a casual "walk-around" with the visual check for the general condition delivered mainly by the flight crew, to a detailed inspection involving complete disassembly and the use of complex inspection aids delivered by the qualified engineering staff. Time intervals between successive inspections vary with a model of aircraft involved and types of operations being conducted. In some instances an aircraft is inspected after a specified number of flight hours have been accumulated. During each inspection, appropriate check-lists must be used to ensure that no items are forgotten or overlooked. Moreover, a special inspection can be performed out of schedule when an event occurs which is out of the ordinary care and use of the aircraft, such as hard or overweight landing, severe turbulence, over " $\mathrm{g}$ " overload, lightning strike, fire damage, or flood damage [8]. 
A variety of non-destructive testing and evaluation (NDT\&E) methods have been developed to enable a qualitative and sometimes also a quantitative analysis of the integrity of composite structures. The principal difference between the qualitative and quantitative methods is that the first group is suitable only for damage detection, whereas the latter enables flaws to be also quantified with respect to their location and/or size. The most common methods used for the inspections of structural aircraft components are shortly introduced in the following subsections. Since the ultrasonic inspection has been by far the most popular among the non-destructive inspections (NDIs) of composites $[14,19]$, this method is presented in more detail.

\section{VISUAL AND PENETRANT INSPECTION}

Visual inspection is the oldest and most common inspection form used for aircraft. However, it has to be mentioned that in accordance with the EN 4179/ NAS 410 NDI personnel certification scheme this method is not regarded as the NDI but rather as maintenance inspection delivered by a qualified maintenance crew. It is usually one of the first methods used for locating potential defect areas. Once located, the areas of interest are more thoroughly examined [20]. Approximately $80 \%$ of all NDI procedures are accomplished by the direct visual methods [10]. Various tools can be used to aid this inspection procedure, such as flash-lights, inspection mirrors, magnifying instruments, borescopes, or video scanners $[10,7]$. Moreover, a dye-penetrant can be applied to detect material discontinuities that may not be evident to the ordinary visual inspection. The basic objective of the penetrant inspection is to increase the visible contrast between the defect and the underlying material. A high penetrating dye is sprayed on the composite element and it enters the surface opening of the discontinuity. The excess penetrant is removed, and a developer material (usually a dry white powder) is then applied in order to draw the liquid from the suspected flaw to reveal the discontinuity. The visual evidence of the suspected defect can then be seen either by the colour contrast in normal visible white light or by fluorescence under black ultraviolet light. The major limitation of the penetrant inspection is that it can detect only those discontinuities that are open to the surface [10]. The typical applications of visual inspections include the detection of scratches, resin starvation, resin richness, wrinkles, ply bridging, cracks, impact damage, foreign inclusions, blisters, etc. [9, 7]. Although the visual inspection is economical and easily performed, it is, however, limited by the inspector's sight [7], with the internal flaws such as delaminations and disbonds cannot be detected [9]. 


\section{TAP-TESTING}

Tap test is a resonance test widely used for a quick evaluation of aircraft surfaces to detect the presence of delamination or debonding, as well as voids [10,7]. The inspected surface is tapped with a tool producing a constant frequency and the acoustic response of the structure is analysed. Several inexpensive tools have been designed for tap tests, from coins to hammers, as well as Woodpeckers - automated hammers that offer selectable tapping intensity and frequencies [7]. The acoustic response is compared with that of a well known area. Tap testing is limited to finding relatively shallow defects in skins less than ca. $2 \mathrm{~mm}$ in thickness. This method is generally qualitative [7] and its accuracy depends on the inspector's subjective interpretation of the test response $[10,9]$.

\section{EDDY CURRENT INSPECTION}

Eddy current techniques are electromagnetic tests based on analysing conductivity and permeability variations of the material under inspection. A primary magnetic field is generated when the alternating current is applied to an induction coil. Eddy currents are induced in a test element when the coil is placed near that element. The alternating current in the coil induces an alternating magnetic field in the element which causes the flow of eddy currents. Thickness changes or flaws in the test element influence the flow of eddy currents and change the impedance of the coil $[10,13]$. Eddy current testing is particularly well-suited for detection of service-induced cracks [10], but also corrosion, surface breakings $[3,10]$, missing carbon fibre bundles [13], porosity, voids and foreign inclusions [20]. The limitations of this qualitative method include the limited penetration depth and the undetectability of the damage parallel to the scan direction. Moreover, only electrically conductive materials can be inspected [3].

\section{SHEAROGRAPHY}

Speckle shearing interferometry, or shearography, is an interferometric optical measurement technique that uses the laser speckle and the shear effect. The laser speckle effect occurs when light is scattered from an optically rough surface whose topographical features are greater than the wavelength of the light. When this occurs, a complex granular pattern is produced as the result of the interference of light scattered from different points on the surface. Shearography is derived from a similar technique - Electronic Speckle Pattern Interferometry (ESPI), which is related to holography. The basic principle of shearography involves the comparison of the speckle patterns recorded before and after applying a load to the component under test. The correlation of the speckle patterns offset by the shear vector produces a fringe pattern with the fringes representing the contour maps of the measurands. For the composite material testing, a static 
loading (vacuum, pressure or thermal), or dynamic loading - by inducing a resonant vibration (e.g. with the use of a piezoelectric shaker or an acoustic wave) are often used. Shearography is particularly well suited to industrial testing compared with holography and ESPI because of its resilience to environmental disturbances owing to short coherence length requirements, and its direct sensitivity to surface strain [12]. This technique is particularly effective in locating debonds and delaminations [10], as well as cracks [16]. It enables identifying the size and shape of subsurface defects. Shearography is a rapid technique allowing on-aircraft inspections of structures without their removal, as well as inspections of large areas (fuselages and wings) in seconds $[10,7]$.

\section{THERMOGRAPHY}

Infrared thermography is an NDI technique that uses radiant electromagnetic thermal energy. Thermographic cameras are used to detect infrared radiation of a tested object and produce an image of that radiation. The presence of a defect is indicated by an abnormal temperature distribution when the tested component is subject to normal heating or cooling conditions typical of the in-service life (passive thermography), and/or when artificially heated or cooled (active thermography) [10]. Active thermography involves heating the object's surface using an external heat source and observing how the surface temperature decays with time as the heat penetrates or diffuses into the material. Internal flaws in the material show up by variations in both the surface temperature distribution and decay rate. Active thermography can utilise an optical/external excitation, e.g. using a lamp, laser, fluid jets (Lock-in thermography, Pulsed thermography, Step thermography), or mechanical/internal excitation (Vibrothermography) [18]. Thermography can be used for detecting impact damage, inclusions [11], delamination, debonds, cracks, and water ingress $[7,9]$. Thermographic methods are suitable for fast inspecting of large areas and can be quantitative, but their accuracy is dependent on thermal conductivity of the tested component [7] and are most effective for thin laminates or for near-surface defects [9].

\section{ACOUSTIC EMISSION TESTING}

Acoustic emission (AE) methods are based on the principle that a defective structure should generate an acoustic answer, i.e. a transient elastic wave, by sudden redistribution of stress [7]. The AE sources are the fracture mechanisms or deformation phenomena such as crack initiation and growth, micro-structural separation, and dislocations between material phases. The $\mathrm{AE}$ inspection involves the placing of acoustical-emission sensors at various locations on the aircraft structure and then applying an external load or stress [8]. 
In the case of the aircraft fuselage the pressure-induced stress can be applied [10]. There are several disadvantages to this method. First of all, it is a qualitative method. Secondly, flaws that do not move or grow cannot be detected [20]. Moreover, the noise, attenuation and anisotropic properties of polymer matrix composites (PMCs) may pose challenges for the AE data analysis [15]. Slight movement of riveted or bolted joints can also generate acoustic signals. These unwanted AE sources significantly complicate the AE tests of complex structures [10]. AE monitoring of PMCs can be used to detect matrix cracking, delamination, debonding, or fibre breakage. AE measurements can be also used for real-time and continuous monitoring of the structure condition $[15,3]$.

\section{RADIOGRAPHIC AND TOMOGRAPHIC INSPECTIONS}

Radiography is based on the principle of absorption of the penetrating radiation (X-ray or gamma-ray [4]) by a tested component. Variances in absorption of the radiation occur due to differences in density, thickness, sizes, shapes, absorption characteristics, or due to the presence of defects in the material. During a radiographic inspection, the unabsorbed radiation that passes through the tested element is recorded on a radiographic film, fluorescent screens, or other radiation monitors [10,3]. Radiography successfully reveals inner defects of composite elements, such as delamination, cracks, foreign inclusions, voids, and water moisture. However, since the method records changes in a total density through the thickness, it is not a suitable method for detecting defects that are not parallel to the beams [9]. Other drawbacks of this method include the high costs and the requirement of strict health regulations.

Computed Tomography (CT) is another radiological technique with enhanced flaw detection and location capabilities. Unlike film radiography, CT involves the generation of cross-sectional views instead of a planar projection [10]. CT enables displaying the three-dimensional views of the inspected component and better detection of small defects such as pores, voids, cracks, etc. [7]. The spatial resolution of the current $\mathrm{CT}$ technology is lower than $1 \mu \mathrm{m}$ [17], which allows detection and precise characterisation of even a single fibre breakage in an FRP composite structure. Analysis of tomograms (CT scans) is difficult due to existence of numerous artefacts, which usually appear in the form of streaking, shading, rings, or distortion of the image [1] due to the very high sensitivity of this method. CT has the serious limitation regarding the possible dimensions of tested elements, i.e. they must fit in a tomograph chamber. Therefore, CT is suitable only for laboratory tests and cannot be used neither in field conditions nor as a regular NDT method for aircraft composite elements. 


\section{ULTRASONIC INSPECTION}

Ultrasonic testing (UT) is one of the most universal NDT methods used for composite structures [6] and is the primary inspection method used in the aircraft/aerospace industry [14]. The reason for this wide applicability of UT is its high sensitivity to various damage types commonly found in composites, such as delaminations, debonds, foreign object inclusions, cracks, voids, and porosity $[10,21]$. Using this method it is possible to precisely determine the geometry of internal defect or damage, its surface area and the depth location.

Ultrasonic inspections rely on the fact that elastic waves propagate in solid materials and are reflected at the interfaces and by internal flaws or damage (material separations, inclusions, etc.). This method involves the transmission of ultrasonic waves into a test material and observation of the reflected waves (Pulse-Echo technique), or the transmitted waves (Through-Transmission technique). Pulse-Echo systems require only one-sided access to the element being tested, thus has practically used for in-service inspections, whereas the Through-Transmission technique is widely used in manufacturing. The most common UT methods apply longitudinal and transverse (shear) waves. However, other forms of the elastic waves propagation including Rayleigh and Lamb waves are also used. Most ultrasonic transducers operate on the piezoelectric principle of transconductance, i.e. they transmit an ultrasonic pulse when excited by an extremely short electrical discharge, and generate an electrical signal when they receive the returned ultrasonic signal [2]. This mutual conversion is accomplished by a plate of polarized ceramic or crystalline material with electrodes on the opposite surfaces. Transducers are designed for contact testing or immersion testing. Most contact transducers require applying a coupling agent (e.g. water, thin film or oil, contact paste, or glycerin) between the probe and the test element surface because air attenuates the most of the ultrasonic energy. In the immersion testing, the elastic waves are transmitted into the material through a water path or a liquid column. Flaw detection is possible because of the difference in acoustic impedance of various materials, which is a measure of resistance to propagation of ultrasonic wave in a material. Ultrasonic waves are reflected at the interface of two different materials or other discontinuities, when the mismatch in acoustic impedance occurs [20]. The general principles of ultrasonic examination are presented in more detail in the PN-EN ISO 16810:2014 standard [22].

It should be mentioned that there is also an air-coupled UT technique. It eliminates the necessity for a liquid couplant and can be applied to such structures as a honeycomb sandwich with perforated face sheets. The greatest challenge in air-coupled UT is the enormous loss of ultrasonic energy at the air-solid interface; therefore, special transducer types are used. For a piezoceramic type of 
an air-coupled transducer, the special material layers are used to bridge the high acoustic impedance of the transducer element and the low impedance of air [14].

Appropriate processing and analysis of ultrasonic scans allow for the damage detection, localisation, characterisation, and quantification.

\section{OTHER ULTRASONIC TECHNIQUES FOR BOND TESTING}

Apart from the traditional UT methods described above, the integrity of bonds in the multi-layered adhesively bonded structures can be tested using bond testers. Modern bond testers operate in three testing modes - a Resonance, a Pitch-Catch and a Mechanical Impedance Analysis (MIA) mode. Bond testing can be regarded as an electronic form of tap-testing, but with continuous rather than impulse excitation $[11,5,8]$. Compared to the conventional UT techniques, bond testers operate at lower frequencies, typically in the range between $4 \mathrm{kHz}-400 \mathrm{kHz}$ [5]. The Resonance, Pitch-Catch, and MIA testing modes all have several similarities while the measurement metric is a variation in the amplitude and/or phase of the elastic wave transmitted into the material. The second common principle is that the result is a relative measurement between a good and a flawed area of the structure. These modes vary, among others, in terms of a way of coupling, a frequency range (a swept or fixed frequency; a low, medium or high frequency), and sensitivity to various damage types and sizes. The bond testers enable detection of delamination, disbonds, impact damage, foreign objects, voids, porosity [5, 7], as well as water ingress in honeycomb sandwich structures [7]. The main disadvantage of bond testing is that it is qualitative and suitable only for near-surface damage detection [11].

\section{CONCLUSIONS}

Among many NDT\&E methods described in the paper, ultrasonic testing is one of the most commonly applied owing to its capabilities of detecting various types of flaws and damage inside composite structures and evaluating their location and geometrical properties. However, all of the methods described have both advantages and limitations. In order to efficiently conclude about the structural integrity of inspected aircraft components, several inspection methods must be applied. This paper was based on the review and research study reported in a doctoral dissertation of the author [23].

\section{REFERENCES}

[1] Barrett J. F. and Keat N. (2004): Artifacts in CT: recognition and avoidance. RadioGraphics 24(6): pp. 1679-1691.

[2] Berke M. (1996): Nondestructive Material Testing with Ultrasonics: Introduction to the Basic Principles. Krautkamer GmbH \& Company. 
[3] Bowkett M. and Thanapalan K. (2017): Comparative analysis of failure detection methods of composites materials'systems. Systems Science \& Control Engineering 5(1): pp. 168-177.

[4] Civil Aviation Authority (2010): Civil Aircraft Inspection Procedures: Part I - Basic. Himalayan Books. New Delpi, India.

[5] Crompton M. (2014): Ultrasonic bond testing as a quality tool: with the growth in the use of adhesive bonding and composites, bond testing is seeing its second wind. Quality 53(7): pp. S4-S4.

[6] Davis J. R. (1989): ASM Handbook: Nondestructive Evaluation and Quality Control. Vol. 17. ASM International. Materials Park, OH.

[7] Ehrhart B., Valeske B. and Bockenheimer C. (2013): 9 - Non-destructive evaluation (NDE) of aerospace composites: methods for testing adhesively bonded composites. In: Non-Destructive Evaluation (NDE) of Polymer Matrix Composites, V. M. Karbhari (Ed.). Woodhead Publishing Series in Composites Science and Engineering. Woodhead Publishing: pp. 220-237.

[8] Federal Aviation Administration (2008): Aviation Maintenance Technician Handbook: General. U.S. Department of Transportation. Oklahoma City, Oklahoma, US.

[9] Federal Aviation Administration (2012): Advanced Composite Materials. Aviation Maintenance Technician Handbook-Airframe. Vol. 1. U.S. Department of Transportation.

[10] Finch R., Fischer R., Grimes M., Stits R. and Watkins W.: Advisory Circular 43.13-1B - Acceptable Methods, Techniques, and Practices - Aircraft Inspection and Repair. Federal Aviation Administration.

[11] Fowler T. J., Kinra V. K., Maslov K. and Moon T. J. (2001): Research Report: Inspecting FRP Composite Structures with Nondestructive Testing. Technical Report FHWA/TX-03/1892-1. Center for Transportation Research, The University of Texas at Austin.

[12] Francis D. (2013): 4 - Non-destructive evaluation (NDE) of composites: introduction to shearography. In: Non-Destructive Evaluation (NDE) of Polymer Matrix Composites, V. M. Karbhari (Ed.). Woodhead Publishing Series in Composites Science and Engineering. Woodhead Publishing: pp. 56-83.

[13] Heuer H., Schulze M. H. and Meyendorf N. (2013): 3 - Non-destructive evaluation (NDE) of composites: eddy current techniques. In: Non-Destructive Evaluation (NDE) of Polymer Matrix Composites, V. M. Karbhari (Ed.). Woodhead Publishing Series in Composites Science and Engineering. Woodhead Publishing: pp. 33-55.

[14] Hsu D. K. (2013): 15 - Non-destructive evaluation (NDE) of aerospace composites: ultrasonic techniques. In: Non-Destructive Evaluation (NDE) of Polymer Matrix Composites, V. M. Karbhari (Ed.). Woodhead Publishing 
Series in Composites Science and Engineering. Woodhead Publishing: pp. 397-422.

[15] Huang J. Q. (2013): 2 - Non-destructive evaluation (NDE) of composites: acoustic emission (AE). In: Non-Destructive Evaluation (NDE) of Polymer Matrix Composites, V. M. Karbhari (Ed.). Woodhead Publishing Series in Composites Science and Engineering. Woodhead Publishing: pp. 12-32.

[16] Hung Y. Y., Yang L. X. and Huang Y. H. (2013): 5 - Non-destructive evaluation (NDE) of composites: digital shearography. In: Non-Destructive Evaluation (NDE) of Polymer Matrix Composites, V. M. Karbhari (Ed.). Woodhead Publishing Series in Composites Science and Engineering. Woodhead Publishing: pp. 84-115.

[17] Kastner J., Plank B., Reh A., Salaberger D. and Heinzl C. (2013): Advanced X-Ray Tomographic Methods for Quantitative Characterisation of Carbon Fibre Reinforced Polymers. Proc. 4th International Symposium on NDT in Aerospace. Augsburg: pp. 1-9.

[18] Ley O. and Godinez V. (2013): 12 - Non-destructive evaluation (NDE) of aerospace composites: application of infrared (IR) thermography. In: Non-Destructive Evaluation (NDE) of Polymer Matrix Composites, V. M. Karbhari (Ed.). Woodhead Publishing Series in Composites Science and Engineering. Woodhead Publishing: pp. 309-336e.

[19] Meola C. and Carlomagno G. M. (2013): 14 - Non-destructive evaluation (NDE) of aerospace composites: detecting impact damage. In: Non-Destructive Evaluation (NDE) of Polymer Matrix Composites, V. M. Karbhari (Ed.). Woodhead Publishing Series in Composites Science and Engineering. Woodhead Publishing: pp. 367-396.

[20] Mix P. E. (2005): Introduction to Nondestructive Testing: a Training Guide. 2nd edn. John Wiley \& Sons.

[21] Smith R. A. (2009): Composite defects and their detection. In: Encyclopaedia of Life Support Systems, R. Rawlings (Ed.). Vol. 3 of Materials science and engineering. UNESCO: pp. 103-143.

[22] Standard (2014): PN-EN ISO 16810:2014, Non-destructive testing - Ultrasonic testing General principles.

[23] Wronkowicz A. (2018): Non-destructive evaluation of composite aircraft elements based on ultrasonic testing and image analysis. Doctoral dissertation. Politechnika Śląska, Gliwice. 